\title{
SEGURANÇA PRIVADA E INFRAESTRUTURA CRÍTICA: DESAFIOS PARA A GOVERNANÇA DA SEGURANÇA DOMÉSTICA DOS EUA PÓS 11 DE SETEMBRO ${ }^{1}$
}

\author{
Cleber da Silva Lopes ${ }^{2}$
}

\begin{abstract}
Resumo
A governança da segurança dos EUA, após os atentados de 11 de setembro de 2001, tem sido marcada pela participação do setor de segurança privada. Externamente, os EUA têm feito uso de empresas militares privadas para dar apoio ou proteger seus recursos materiais e humanos em zonas de conflito. Internamente, as ameaças de ataques contra a infraestrutura dos EUA alçaram o setor de segurança privada à condição de parceiro chave na promoção da segurança nacional. Uma literatura crescente tem se debruçado sobre o uso de empresas militares privadas em conflitos internacionais, mas o papel da segurança privada na promoção da segurança doméstica dos EUA tem sido largamente negligenciado. 0 objetivo desse trabalho é discutir alguns dos desafios e implicações que a segurança privada coloca para a governança da segurança nacional dos EUA no período pós-11 de setembro.
\end{abstract}

Palavras-Chave: Estados Unidos. Segurança privada. Infraestrutura crítica. Segurança doméstica.

\footnotetext{
${ }^{1} 0$ autor agradece 0 apoio do Observatório Político dos Estados Unidos (OPEU) para a realização deste artigo, que teve versão prévia publicada no site do OPEU, seção Estudos e Análises de Conjuntura, n. 6, outubro de 2011. Versão preliminar desse artigo também foi apresentada no $3^{\circ}$ Encontro da Associação Brasileira de Relações Internacionais (ABRI).

${ }^{2}$ Doutorando do Departamento de Ciência Política da Universidade de São Paulo, Brasil. cleber1lopes@hotmail.com
} 


\title{
Private SECURITY AND CRITICAL INFRASTRUCTURE: THE CHALLENGES FOR THE GOVERNANCE OF U.S. HOMELAND SECURITY AFTER SEPTEMBER 11
}

\begin{abstract}
The governance of U.S.A. homeland security since the terrorist attacks of September 11, 2001 has been marked by the participation of the private security industry. Externally, the U.S.A. has been using the services of private military companies to support or protect its human and material resources in conflict zones. Internally, threats of attacks against United State's infrastructure have raised the status of the private security industry to key partner in promoting homeland security. A growing literature has been addressing the use of private military companies in international conflicts, but the role of private security in promoting U.S.A homeland security has been largely neglected. The aim of this paper is to discuss some of the challenges and implications that private security imposes to the governance of U.S.A homeland security post-September 11.
\end{abstract}

Keywords: United States of America. Private security. Critical infrastructure. Homeland security.

\section{INTRODUÇÃO}

O termo governança vem sendo usado pela literatura acadêmica para dar conta de uma grande variedade de fenômenos, que vão desde práticas de governar o sistema internacional, na ausência de um governo global, até 0 reconhecimento de que 0 Estado não é o único ator que exerce poder nas sociedades contemporâneas (PICCIOTTO, 2006, p. 2-3; BURRIS; KEMPA; SHEARING, 2008, p. 3-4). Na área de segurança, a noção de governança é cada vez mais usada para se referir às ações de uma pluralidade de atores estatais e não estatais empenhados em oferecer garantias de proteção a indivíduos e/ou instituições (WOOD; DUPONT, 2006, p. 1-10).

A governança da segurança dos EUA no período pós-11/09 tem sido marcada pela participação de empresas de segurança privada. Externamente, os EUA têm feito uso de empresas militares privadas para dar apoio ou proteger seus recursos materiais e humanos em zonas de conflito, especialmente no Iraque e no Afeganistão. Internamente, as ameaças de ataques terroristas contra a infraestrutura dos EUA alçaram o setor de segurança privada à condição de parceiro chave na promoção da segurança doméstica.

Uma literatura crescente tem se debruçado sobre o uso de empresas militares privadas em conflitos internacionais, mas o papel da segurança privada 
na promoção da segurança doméstica dos EUA tem sido largamente negligenciado. 0 objetivo desse trabalho é discutir alguns dos desafios e implicações que a segurança privada coloca para a governança da segurança nacional dos EUA, no período pós-11/09. De que forma a segurança privada desafia o modo como tradicionalmente pensamos assuntos de segurança nacional? Quais dificuldades a segurança privada coloca para a governança da segurança doméstica dos EUA? 0 que 0 governo dos EUA está fazendo para superar essas dificuldades? Este artigo procura explorar essas questões.

0 texto está organizado em duas partes, seguidas de breves considerações finais. Na primeira, procuro mostrar como a segurança privada se tornou uma parceira chave na promoção da segurança interna dos EUA. Na segunda parte discuto algumas das implicações e dos desafios postos pelo envolvimento da segurança privada em temas de segurança nacional. Nas considerações finais sumarizo os argumentos do trabalho e faço alguns breves comentários gerais sobre o futuro da governança da segurança doméstica dos EUA.

\section{A Segurança Privada nos EUA: de tropa de CHOQUE PRIVADA À PARCEIRA NA PROMOÇÃO DA SEGURANÇA DOMÉSTICA}

\section{O cenário anterior a 11 de setembro}

A segurança privada tem sido definida como um setor que vende equipamentos e serviços para proteger informações, pessoas e propriedades contra ocorrências indesejadas que possam acarretar perdas. 0 segmento que vende serviços de proteção normalmente se divide entre aquele formado por organizações que constituem e mantêm corpos próprios de segurança (private security in-bouse ou segurança privada orgânica) e aquele formado por empresas especializadas na prestação de serviços de segurança para terceiros (contract private security ou segurança privada contratada) (SHEARING; STENNING, 1981, p. 194-198).

0 setor de segurança privada dos EUA surgiu no final do século XIX e começo do século XX como resultado de três tendências: o crescimento dos sindicatos e da sindicalização, que levou a grandes greves que estimularam 0 uso de agentes provocadores e guardas privados como forças dissuasórias de movimentos de reivindicação; a expansão da fronteira em direção ao oeste, que trouxe a necessidade de proteger o dinheiro, o ouro e outros valores que eram 
transportados por longas distâncias; e a incapacidade da polícia pública para prevenir e investigar crimes (MANNING, 2006, p. 110-111).

0 envolvimento da segurança privada em conflitos trabalhistas, no final do século XIX e começo do século XX, contribuiu para que esse setor de serviços fosse inicialmente percebido pelo governo americano como uma tropa de choque privada que ameaçava os direitos civis dos cidadãos e a paz e segurança de toda a comunidade. Essa visão governamental sobre a segurança privada foi expressa em relatórios do Congresso, que mostram grande preocupação com as práticas de policiamento privado das companhias de mineração e ferrovias, especialmente na forma como elas tratavam a mão de obra (SHEARING, 2003, p. 431-36). Esses relatórios contam histórias em que essas corporações utilizavam exércitos privados agressivos para promover uma ordem em desacordo com a paz e o interesse público. Uma das histórias mais conhecidas é o Massacre de Homestead, resultado de uma batalha sangrenta entre grevistas e agentes de segurança privada da Agência Nacional de Detetives de Pinkerton, ocorrido em 1892, na Carnegie Steel Company, Pennsylvania.

A visão da segurança privada como uma tropa de choque privada que ameaça as liberdades e a ordem pública dos EUA, expressou e consolidou a consciência política de um Estado centralizado, na qual o policiamento deveria ser um monopólio público e a segurança privada admitida apenas como expressão do direito liberal de autoproteção. Segundo Shearing (2003, p. 436), essa política de reconhecer o policiamento como legítimo em sua manifestação pública e como perigoso em sua expressão privada foi tão bem sucedida que em meados do século XX a segurança privada era vista como algo anacrônico e que havia declinado em virtude da ascensão da "nova polícia".

Essa situação mudou na segunda metade do século XX. As estatísticas dão conta que a partir dos anos 60 a segurança privada cresceu de forma exponencial nos EUA. 0 setor de segurança privada que opera por contrato cresceu a uma taxa anual de 7,4\% na década de 60. Por volta de 1975, a relação entre polícia pública e segurança privada (orgânica e contratada) nos EUA era de 0,9 por 1; em meados da década de 80 essa proporção já era de 1 por 2, tendo aumentado para algo próximo a 1 por 3 na década de 90 (SHEARING, 2003, p. 437). Esse crescimento da segurança privada não foi particular aos EUA. Ele ocorreu, mais cedo ou mais tarde, com maior ou menor intensidade, em diversas partes do mundo, configurando o 
que Shearing e Stenning (1981, p. 193) chamaram de "revolução silenciosa" nos sistemas de policiamento e controle social de vários países 3 .

0 crescimento da segurança privada nos EUA foi acompanhado de uma mudança na visão negativa da segurança privada. Como mostrou Shearing (2003, p. 436-449), essa mudança foi promovida por dois influentes estudos comissionados pelo governo americano nas décadas de 70 e 80, um realizado pela RAND Corporation e assinado por Kakalik e Wildhorn (1972), e outro realizado pela Hallcrest Corporation e assinado por Cunningham e Taylor (1985).

0 estudo da RAND Corporation articulou a ideia de que a segurança privada não era uma tropa de choque privada, mas uma indústria como outra qualquer do setor de serviços. Tratando a segurança como uma commodity, o relatório da $R A N D$ transformou o tema da segurança de uma questão de política e soberania, a ser respondida em termos absolutos, numa questão de economia e eficiência, a ser abordada em termos de equilíbrio, proporção e grau. Essa mudança dos termos do debate foi completada com a idéia de que a segurança privada era um parceiro júnior das forças policiais, pois desempenhava tarefas simples de autodefesa (vigiar espaços, relatar crimes, controlar acessos e prevenir perdas) que a polícia não tinha nem a vocação e nem os recursos para realizar. Essa noção de parceira foi aprofundada uma década mais tarde no relatório da Hallcrest Corporation, em que se argumentou que a segurança privada não era um simples meio de autodefesa, mas uma indústria relacionada ao crime e ao medo do crime que estava assumindo as mesmas funções da polícia e ajudando ativamente no combate à criminalidade. Com essa interpretação, a segurança privada deixou de ser um parceiro júnior para se tornar um parceiro em pé de igualdade da polícia.

Esses dois relatórios deram vida a uma concepção laissez-faire na área de segurança, incutindo no governo americano a ideia de que a segurança privada era uma indústria vigorosa, em franca expansão e com um "grande papel protetor na vida de nação" (CUNNINGHAM; TAYLOR, 1985, p. 163). Essa percepção orientou um extenso programa de reformas visando engajar o setor de segurança privada na luta contra o crime, especialmente por meio de parcerias com a polícia e o aumento da troca de informação e intercâmbio de pessoal e experiências ${ }^{4}$. Paralelamente, essa concepção também orientou um programa

\footnotetext{
${ }^{3}$ Para dados comparativos de diversas partes do mundo, ver Dijk (2008) e Steden e Sarre (2010).

${ }^{4}$ Para uma revisão da literatura sobre as iniciativas de parceria entre segurança pública e segurança privada nos EUA, ver o relatório da Hallcrest assinado por Connors e Cunningham, Ohlhausen
} 
de terceirização junto às forças armadas e agências do Departamento de Defesa, que levou ao envolvimento de empresas militares privadas em atividades que até o final dos anos de 1980 eram desempenhadas com exclusividade por agências estatais (AVANT, 2007, p. 181-184; SINGER, 2001/2002, p. 197-198).

\section{O cenário pós-11 de setembro}

Quando os atentados de 11 de setembro ocorreram, a segurança privada já era responsável por uma parte importante do suprimento de proteção disponível no interior dos EUA, incluindo a proteção de setores de infraestrutura considerados alvos potenciais de ataques terroristas. A segurança privada era (e continua sendo) largamente empregada em grandes eventos de massa, sistemas de transportes, centrais de produção/distribuição de energia, redes de telecomunicações, estações de tratamento de água e muitos outros setores de infraestrutura. Dados do Bureau of Labor Statistics (BLS) para o ano de 2003 mostram que havia cerca de 1 milhão de guardas trabalhando nos Estados Unidos, contra 654 mil policiais5. A tabela 1 mostra o número de guardas de segurança terceirizados (contract guards) e orgânicos (staff guards) e as respectivas áreas nas que atuavam.

Tabela 1: Total de Guardas de Segurança Empregados - EUA, 2003

\begin{tabular}{|l|c|c|c|c|}
\hline & $\begin{array}{l}\text { Instalações } \\
\text { Privadas }\end{array}$ & $\begin{array}{c}\text { Instalações } \\
\text { Governamentais }\end{array}$ & Aeroportos* & Total \\
\hline $\begin{array}{l}\text { Agentes de segurança } \\
\text { terceirizados (contract } \\
\text { guards) }\end{array}$ & \multicolumn{2}{|c|}{531.000} & 2.000 & 533.000 \\
\hline $\begin{array}{l}\text { Agentes de segurança } \\
\text { orgânicos (staff guards) }\end{array}$ & 351.000 & 85.000 & 53.000 & 489.000 \\
\hline Total & \multicolumn{2}{|c|}{967.000} & 55.000 & 1.022 .000 \\
\hline
\end{tabular}

Fonte: Elaborado por Pafomak (2004a) a partir de dados do Bureau of Labor Statistics (BLS);

* Guardas responsáveis pela inspeção de passageiros e bagagens.

Os guardas de segurança terceirizados representavam aproximadamente $52 \%$ de todos os guardas ocupados naquele ano. Dados de outras fontes indicam

(1999). Assim como os demais relatórios citados nesse trabalho, este também foi patrocinado pelo governo americano.

${ }^{5}$ Esse número exclui pessoas ocupadas na indústria da segurança privada como instaladores de equipamentos de proteção, monitores de sistemas eletrônicos de segurança, analistas de riscos e consultores. Considerando esses profissionais, o número de pessoas trabalhando na indústria da segurança privada nos EUA do começo deste século era de 1,8 milhões. 
que esse setor teve uma receita de aproximadamente US\$ 11 bilhões em 2003, montante que representou cerca de $30 \%$ da receita total da indústria de segurança dos EUA. Esse setor é bastante heterogêneo. Há desde milhares de pequenas empresas locais e regionais que prestam serviços simples de vigilância e controle de acesso, até grandes empresas nacionais e estrangeiras, com capacidade de prestar serviços mais especializados para plantas nucleares, grandes eventos, etc. A tabela 2 resume as estatísticas de 2003 sobre as maiores empresas de segurança privada que operam nos EUA. Como mostra a tabela, as quatro maiores empresas foram responsáveis por $50 \%$ da receita da indústria e 35\% dos funcionários ocupados no ano de 2003. As duas maiores empresas são de propriedade estrangeira.

Tabela 2: Principais estatísticas do segmento de segurança privada por contrato - EUA, 2003

\begin{tabular}{|l|r|r|r|r|}
\hline \multicolumn{1}{|c|}{ Empresas } & Receita & $\begin{array}{c}\text { Participação } \\
\text { no mercado } \\
\mathbf{( \% )}\end{array}$ & $\begin{array}{c}\text { Empregados } \\
\left(\mathbf{n}^{\circ} \mathbf{)}\right.\end{array}$ & $\begin{array}{c}\text { País dos } \\
\text { proprietários }\end{array}$ \\
\hline Securitas USA. (Securitas) & 2608 & 23,7 & 100.000 & Suécia \\
\hline Wackenhut (Group 4 Securicor)* & 1489 & 13,5 & 38.000 & Reino Unido \\
\hline Allied / Barton & 900 & 8,2 & 36.000 & Estados Unidos \\
\hline Akal Security* & 500 & 4,5 & 8.000 & Estados Unidos \\
\hline Guardsmark & 465 & 4,2 & 18.000 & Estados Unidos \\
\hline TransNational Security Grp. & 386 & 4,0 & 15.000 & Estados Unidos \\
\hline U.S. Security Associates & 375 & 3,5 & 17.000 & Estados Unidos \\
\hline Initial (Rentokil-Initial)* & 293 & 3,4 & 14.000 & Reino Unido \\
\hline ABM Security Services & 250 & 2,7 & 12.000 & Estados Unidos \\
\hline Cognisa (Group 4 Securicor) & 146 & 1,3 & 6.000 & Reino Unido \\
\hline Demais empresas & 3610 & 31,0 & 258.000 & Estados Unidos \\
\hline Total EUA & 11022 & 100,0 & 522.000 & \\
\hline
\end{tabular}

Fonte: Elaborado por Pafomak (2004b) a partir de dados de arquivos regulatórios, relatórios anuais, páginas da Web e imprensa

* Inclui as operações de seguranças americanos fora dos EUA

Não há dados disponíveis sobre quem contrata os serviços de segurança ofertados por essas empresas. Mas, segundo Parfomak (2004a), não há dúvidas de que muitos guardas prestam serviços em organizações consideradas alvos potenciais de ataques terroristas. A Wackenhut, por exemplo, oferece serviços de guarda a 30 plantas nucleares dos EUA. Já a Akal Security oferece serviços de guarda para bases do Exército e para depósitos de armas. 0 Federal Protective 
Service, força policial responsável pela proteção dos prédios do governo federal, dentre os quais prédios considerados críticos, conta com cerca de 10 mil guardas de segurança contratados. Em relação aos guardas orgânicos (48\% dos guardas ocupados em 2003), Parfomak estimou que cerca de 175 mil trabalhavam em organizações correspondentes aos setores de infraestrutura crítica (38\% dos guardas de segurança própria). Estimativa mais consevadora baseada numa definição mais restrita de infraestrutura crítica apontou a existência de pelo menos 60 mil guardas orgânicos atuando na proteção de áreas fundamentais para a segurança doméstica dos EUA (12\% dos guardas de segurança orgânica).

A vulnerabilidade da infraestrutura crítica dos EUA a ataques terroristas e o papel desempenhado pela segurança privada na proteção dessa infraestrutura foram logo percebidas pelo governo americano, que não demorou a reconhecer na segurança privada uma parceira chave para a promoção da segurança doméstica. Esse reconhecimento começou a ficar evidente em julho de 2002, com a divulgação da National Strategy for Homeland Security. Nesse documento, o governo do presidente George W. Bush tratou a segurança interna como um problema novo, cuja governança dependeria de uma ação compartilhada entre governo federal, governos estaduais, governos municipais e setor privado responsável pela gestão e proteção de infraestruturas críticas. Na National Strategy for the Physical Protection of Critical Infrastructures and Key Assets, o governo explicitamente identificou a segurança privada como a primeira linha de prevenção e de resposta a ataques terroristas. Esse reconhecimento levou a National Strategy e 0 Department of Justice a recomendar aos governos federais, estaduais e municipais o desenvolvimento de regras e parcerias que pudessem fazer com que a segurança privada se tornasse um ator tão engajado na promoção da segurança doméstica quanto tinha sido no combate ao crime, no período anterior a 11/09 (MORABITO; GREENBERG, 2005).

No espaço de pouco mais de um século a segurança privada se transformou de um ator ameaçador e visto com desconfiança pelo governo americano num ator colaborador e visto como parceiro. Inicialmente identificada como parceira no combate ao crime, com as mudanças no cenário doméstico provocadas pelos atentados de 11 de setembro, a segurança privada foi rapidamente elevada à condição de parceira chave para a promoção da segurança doméstica. Essa mudança suscita diversas implicações e desafios para a governança da segurança interna dos EUA, alguns dos quais passo a discutir agora. 


\section{AlguMAS IMPLICAÇÕES E DESAFIOS COLOCADOS PELA SEGURANÇA PRIVADA PARA A GOVERNANÇA DA SEGURANÇA DOMÉSTICA}

\section{Mudanças no debate sobre segurança nacional}

0 novo papel atribuído à segurança privada nos EUA no período pós-11/09 deixou claro que o debate sobre segurança nacional precisa ser alargado para dar conta da presença desse novo ator.

Entendida como a condição relativa de proteção coletiva e individual dos membros de uma sociedade contra ameaças à sua sobrevivência e autonomia (CEPIK, 2001, p. 140-1), a segurança nacional tem sido tratada pela Ciência Política como um problema que depende basicamente da ação do Estado. Políticas de segurança nacional têm sido identificadas com os esforços dos Estados para neutralizar ameaças vitais à sua sobrevivência, por meio de organizações públicas dedicadas à negociação (corpos diplomáticos), obtenção de informações sobre capacidades e intenções (agências de inteligência) e uso de medidas extraordinárias e de força em diferentes graus (organizações policiais e forças armadas). A emergência da segurança privada como ator fundamental para a defesa de recursos considerados essenciais à sobrevivência dos EUA desafia essa forma tradicional de conceber assuntos de segurança nacional.

0 envolvimento da segurança privada na promoção da segurança doméstica também altera o debate até então em vigor sobre a governança da segurança nacional dos EUA. Entre o fim da guerra fria e os atentados de 11/09, o debate sobre esse tema se travou, em grande medida, em torno do papel que agências policiais empenhadas no combate à criminalidade (agências de baixo policiamento) e agências policiais especializadas na coleta e disseminação de informações (agências de alto policiamento) deveriam desempenhar. Durante a guerra fria, os arranjos organizacionais e as políticas de segurança nacional do governo americano foram desenhados a partir de uma polaridade entre interno/externo. Essa polaridade engendrou uma divisão de funções dentro do aparato repressivo do Estado entre agências de alto e baixo policiamento. 0 desaparecimento do inimigo comunista e a emergência do crime organizado e do terrorismo transnacionais na década de 90 colocaram em cheque essa divisão de funções, suscitando intensos debates sobre como integrar as atividades de alto e baixo policiamento de modo a aumentar a efetividade da política de segurança nacional sem ameaçar as liberdades civis (BRODEUR, 2007, p. 28-30). Dentro desse debate, em nenhum momento se levou em consideração o fato de que a 
linha de prevenção e defesa mais imediata contra ataques terroristas eram atores privados. A polêmica sobre como governar a segurança nacional esteve restrita a quais atores estatais deveriam participar (e de que forma) na contenção do crime organizado e na gestão dos riscos de ataques terroristas.

Os atentados perpetrados pela Al Qaeda em 11/09 escancararam o fato de que a governança da segurança nacional dos EUA depende não apenas de uma maior integração entre as agências estatais de alto e baixo policiamento, mas também da participação de atores privados responsáveis pela gestão e proteção das infraestruturas críticas do país. Essa constatação introduz uma nova faceta no debate sobre a governança da segurança nacional dos EUA. Aos problemas tradicionais de efetividade e controle das agências estatais responsáveis pela governançadasegurançanacional, somam-se agora os problemas contemporâneos de coordenação e regulação de atores privados que possuem informações essenciais sobre vulnerabilidades e a capacidade de identificar, mitigar e responder a ameaças terroristas: os proprietários e operadores de infraestruturas críticas e as empresas e profissionais do setor de segurança privada.

0 grande desafio decorrente dessa nova realidade é como fazer com que um setor privado, heterogêneo e que obedece a incentivos distintos dos que operam no setor público, produza políticas de segurança com a efetividade e a transparência requeridas de atores que desempenham funções essenciais à coletividade.

\section{Novos desafios para a governança da segurança doméstica}

Conforme explorado por Kenneth Bamberger (2008, p. 205-214), os EUA têm recorrido a dois modelos para fazer com que atores privados ajam em nome do interesse público: o modelo tradicional de regulação por comando e controle e o modelo neoliberal de auto-regulação voluntária.

0 modelo tradicional de regulação por comando e controle segue as prescrições da teoria econômica da agência: (i) construir regras específicas; (ii) monitorar o comportamento dos atores regulados para saber se as regras estão sendo cumpridas; e (iii) ajustar incentivos - especialmente a ameaça de punição - para que os atores privados se comportem de acordo com as regras fixadas. Nesse modelo de governança top-dow, assume-se que os agentes privados são atores racionais que possuem a capacidade para agir de acordo com regras públicas.

A efetividade da regulação por comando e controle tem sido objeto de muitas críticas, sobretudo da parte de autores filiados à escola anglo-australiana 
de estudos regulatórios. Como resumiu Julia Black (2001, p. 106), as críticas à regulação por comando e controle presentes em muitos dos trabalhos dessa escola fazem referência ao fato de: (i) leis acompanhadas de sanções serem instrumentos de controle pouco sofisticados (falha de instrumentos); (ii) o governo não ter conhecimento suficiente para identificar as causas dos problemas, criar soluções adequadas e identificar não conformidade (falta de informação e conhecimento); (iii) a implementação das regras ser insuficiente (falha na implementação); e (iv) os regulados não serem suficientemente inclinado a obedecer e os reguladores não serem suficientemente motivados a regular em nome do interesse público (falha de motivação e teoria da captura). Segundo Moran (2001, p. 23), esses sintomas patológicos da lei e da sanção como instrumentos de controle não são desconhecidos da literatura sobre regulação norte-americana. Esses sintomas praticamente resumem a crise de legalismo e comando que afligiu os EUA a partir dos anos 60, quando a regulação se estende da esfera econômica para a esfera social.

Os problemas da regulação por comando e controle se apresentam de forma particularmente aguda quando se considera os patrocinadores e os provedores de serviços de segurança privada para infraestruturas críticas. A efetividade desse tipo de regulação depende, em grande medida, ou da existência de um setor regulado suficientemente homogêneo para se submeter a um único conjunto de regras, ou de um setor heterogêneo no qual metas de desempenho possam ser fixadas e os resultados monitorados pelas agências estatais. Nenhuma dessas condições estão plenamente presentes entre os atores privados que participam da governança da segurança doméstica. Tanto o setor de infraestutura crítica, responsável pelo patrocínio dos esforços de proteção, quanto o setor de segurança privada, em grande parte incubido da provisão dos serviços de proteção, são altamente heterogênos. A variedade de patrocinadores e provedores de serviços de segurança torna extremamente difícil baixar regras gerais sobre como os vários agentes devem se comportar diante de ameças que se manifestam sob formas variadas, fluídas e em ambientes tão diversos quanto uma planta nuclear, um terminal de aeroporto e um evento de massa. 0 problema se agrava em razão do fato de que a responsabilidade pela regulação de um conjunto diversificado de infraestruturas críticas recai sob várias agências governamentais e entes federativos. Deixar de lado procedimentos fixos e gerais para realizar regulação e controle por meio de resultados também não é uma solução promissora. A execução de serviços de segurança privada não produz resultados ou produtos claramente mensuráveis, razão pela qual nesse tipo 
de serviço o "principal" geralmente está mais preocupado em regular o processo, a maneira como o serviço é prestado, do que o produto ou o resultado da atividade de segurança executada pelo "agente".

Diante das dificuldades efalhas da regulação estatal por comando e controle, o governo americano tem optado por incentivar a capacidade auto-regulatória dos atores privados, responsáveis pelo patrocínio e provisão de segurança em áreas de infraestrutura crítica. Nesse modelo de regulação bottom-up, as partes privadas não são apenas objeto da regulação, mas também parceiras do empreendimento regulatório. Segundo Bamberger (2008, p. 210), iniciativas dessa natureza podem ser vistas nas orientações da Environmental Protection Agency e da Food and Drug Administration para que os responsáveis pelo fornecimento de água potável e pela produção, processamento e transporte de alimentos nos EUA adotem voluntariamente medidas de segurança genericamente sugeridas pelas agências.

A aposta na capacidade auto-regulatória dos prestadores de serviços de segurança privada tem sido a política predominante nos EUA, que não dispõem de nenhuma lei federal abrangente regulando condições de licenciamento de empresas, requisitos para se tornar guarda e a formação e o treinamento exigido desse tipo de profissional. Como observou Parfomak (2004a), alguns estados fazem exigências de requisitos educacionais e de treinamento para guardas de contrato, mas elas são muito baixas. A única lei federal existente nos EUA é o Private Security Officer Employment Authorization Act (PSOEAA), aprovado em 2003 para regular a prerrogativa de empresas de segurança de realizar checagens de antecedentes criminais de seus funcionários. Além de não tratar dos guardas orgânicos, a lei apenas permite - ao invés de obrigar - a checagem de antecedentes nos cadastros de criminosos e pessoas procuradas pelos governos estaduais e federais. Compete às empresas decidir quais funcionários devem (se é que devem) ter seus antecedentes checados.

Os defensores da auto-regulação voluntária argumentam que delegar aos patrocinadores e provedores de serviços de segurança privada a escolha sobre procedimentos de segurança, permite superar os principais problemas do modelo tradicional de regulação via comando e controle. A auto-regulação permitiria aproveitar o conhecimento e os recursos disponíveis aos atores privados, assegurando respostas velozes e flexíveis aos riscos de ataque terrorista. Problemas de controle estariam supostamente resolvidos em razão da existência de um alinhamento entre os interesses do setor privado, preocupado com a continuidade e a reputação de seus negócios, e do Estado, preocupado em proteger a nação. A 
própria dinâmica de mercado induziria os investimentos privados necessários para que a segurança das infraestruturas críticas fosse assegurada. Esses investimentos passariam necessariamente pela demanda por provedores de segurança privada altamente capacitados, demanda essa que induziria as empresas de segurança a investir em mais cooperação com as agências policiais, qualificação, treinamento e procedimentos de segurança aptos a combater o terrorismo. Assim, incentivos típicos de mercado seriam suficientes para produzir resultados ótimos do ponto de vista do interesse público.

Contudo, como observou Bamberger (2008, p. 211-214), esse modelo de regulação também padece de inúmeros problemas. Segundo o autor, o mercado por si só seria incapaz de fazer com que as empresas invistam o necessário na área de segurança. A fragilidade do mercado estaria relacionada a três fatores. Em primeiro lugar, ataques terroristas que buscam alvos específicos normalmente querem infligir danos de maior alcance, gerando o que os economistas chamam de externalidades. 0 nível de preocupação em relação a um nó em uma rede de telecomunicações, por exemplo, seria determinado pelo custo privado esperado no caso de um ataque terrorista. Esse custo provavelmente não atingiria o nível justificado face ao custo público que o colapso de toda uma rede de comunicação poderia gerar. Em segundo lugar, a natureza interdependente da rede na qual os setores de infraestrutrura crítica operam reduz os incentivos para que investimentos adequados sejam realizados. Dado que uma rede só é protegida se todos os seus nós o forem, a decisão de investir em segurança para a proteção da rede enfrentará problemas de ação coletiva, já que a tendência é a de que atores individuais façam investimentos em segurança apenas se todos os atores da rede o fizerem. Por fim, Bamberger argumenta que a natureza competitiva de muitas indústrias de infraestrutura crítica e do próprio setor de segurança privada agravaria o problema. Como as margens de lucro desses setores são pequenas, o autor considera que o impulso para a eficiência e para a eliminação de redundâncias pode resultar em investimentos escassos em medidas de proteção antiterrorista. Visando obter ganhos de competitividade frente aos concorrentes, empresas de segurança privada podem, por exemplo, não investir em processos apurados de recrutamento e seleção de funcionários, ficando assim vulneráveis a infiltrações e sabotagens.

Bamberger (2008, p. 214) considera ainda que confiar ao setor privado a gestão de recursos vitais à segurança dos EUA também esbarra em problemas organizacionais. As empresas maximizam a eficiência operacional através da especialização do trabalho, segmentação do conhecimento e constituição 
de estruturas de comunicação formalizadas para que informações relevantes cheguem até os gestores. Mas, essa estrutura de comunicação racionalizada não seria tão eficaz na transmissão de informações quando o que está em jogo são problemas imprevistos, acontecimentos estranhos e circunstâncias mutáveis. Esse descompasso entre a estrutura organizacional da empresa, e a natureza dos problemas de segurança com as quais as firmas precisam lidar, contribui para a tomada de decisões erradas. Segundo o autor, a tendência de as pessoas interpretarem situações com base no estoque de conhecimento disponível na organização ou com base na experiência passada também dificulta o processo de tomada de decisão, já que eventos terroristas são relativamente raros e que as organizações raramente dispõem de rotinas sobre como interpretar esse tipo de fenômeno. Esses problemas na tomada de decisão em temas de segurança seriam ainda agravados pela existência de dois tipos de vieses que normalmente acometem os gestores. 0 primeiro seria decorrente da estratégia cognitiva inconsciente de interpretar informações e eventos de modo a confirmar atitudes, crenças e impressões iniciais. 0 segundo envolveria a tendência natural de as pessoas interpretarem informações ambíguas de maneira favorável. Assim, para Bamberger, a inexperiência de administradores e organizações na gestão de riscos decorrentes de ações terroristas, o conservadorismo cognitivo e 0 viés egoísta são fenômenos organizacionais que poderiam induzir os gestores a subestimarem os riscos de serem alvos de atentados e, consequentemente, não realizarem os investimentos privados necessários para a proteção das infraestruturas críticas.

Em que medida essa estratégia de delegar ao setor privado a iniciativa de definir os investimentos e procedimentos necessários à proteção de infraestruturas tem sido efetiva é assunto controverso. Se tomarmos o número de guardas ocupados em infraestruturas críticas como indicador do grau de investimento em segurança privada, fica claro que setores como aeroportos e usinas nucleares aumentaram os seus gastos no período compreendido entre 2001 e 2004. Mas o aumento ocorreu por conta da intervenção do Estado sobre esses setores. Como mostra o Gráfico 1, o número de guardas de segurança empregados nos aeroportos mais do que duplicou após a federalização das atividades de screening ${ }^{6}$, que no final de 2001 passou à responsabilidade da Transportation Security Administration (TSA). Posteriormente, a TSA reduziu a força de trabalho em screening para cerca de 44 mil trabalhadores, mas esse número ainda é 57\% maior do que era em 2001.

\footnotetext{
${ }^{6}$ Screening é o ato de inspecionar pessoas e bagagens com o objetivo de detectar ilegalidades.
} 


\section{Gráfico 1: Evolução do número de agentes de segurança privada que atuam em aeroportos - EUA}

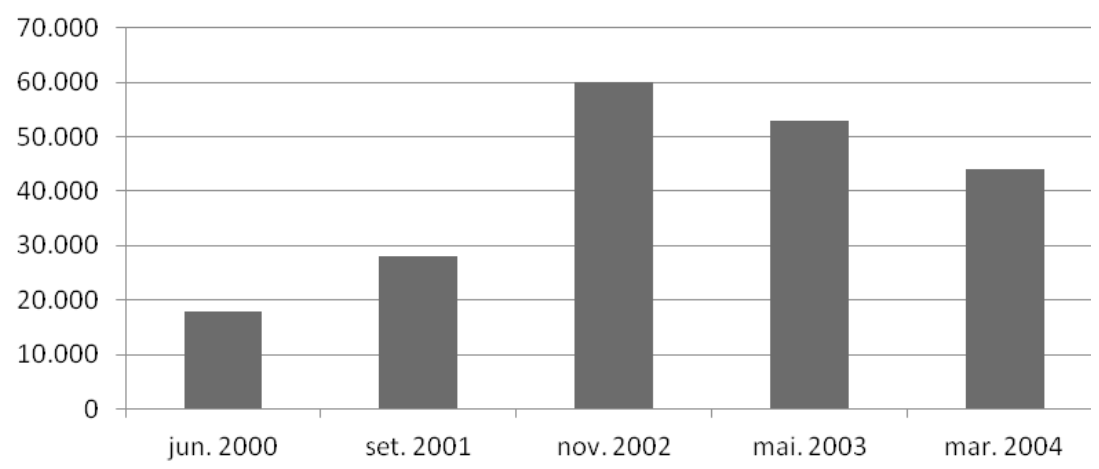

Fonte: Elaborado por Pafomak (2004a) a partir de dados do General Accounting Office (GA0) e

Transportation Security Administration (TSA).

0 incremento de guardas de segurança no momento posterior a setembro de 2001 também ocorreu em usinas nucleares em função de regulação baixada pela Nuclear Regulatory Comission (NRC), que aumentou os requisitos de segurança e o número de guardas orgânicos exigidos para a operação de usinas nucleares. Como resultado, o número total de guardas empregados nas 67 centrais nucleares dos EUA teria aumentado de cinco mil, em 2001, para oito mil, em 2004 (aumento de 60\%).

Levantamento realizado por Parfomak (2004a) junto a alguns centros comerciais de alta visibilidade, instituições financeiras, empresas gestoras de linhas férreas e indústrias do setor químico e de tratamento de água também apontou para um aumento de gastos com agentes de segurança no período pós11/09. Apesar dessas evidências favoráveis, não está claro até que ponto houve um aumento dos gastos com segurança no setor de infraestrutura como um todo e se esse aumento ocorreu de forma sustentada. Segundo o relatório da 9/11 Comission, até 0 ano de 2004 o setor privado estava em sua maior parte despreparado para lidar com ameaças terroristas. Estimativas calculadas pela Comissão mostraram que os gastos com segurança cresceram abaixo de um dígito no contexto pós11/09. Autores como Bamberger (2008) e Flynn (2007) veem nisso a prova de que o mercado, por si só, é incapaz de induzir as empresas a agir de acordo com 0 interesse público de promover a segurança nacional.

Mas esse ponto de vista tem sido contestado por autores como Friedman (2005, p. 26), que acha que os gastos do setor privado dos EUA com segurança 
já são elevados. Segundo Friedman, a melhor forma de combater as ameaças terroristas seria empreender avaliações racionais dos riscos de ataques e prosseguir com os negócios normalmente, ao invés de procurar brechas a serem cobertas. Friedman concorda que em alguns setores - indústrias químicas e arenas que recebem grandes multidões, por exemplo - os riscos de ataques terroristas são reais e o governo pode baixar regulação, caso as empresas não tenham incentivos para investir devidamente em segurança. Todavia, para ele, situações como essas são raras. A vulnerailidade é algo inerente às economias modernas. Grande parte da economia americana depende de redes de comunicação, energia e abastecimento que são muito amplas e impossíveis de serem defendidas por completo. Contudo, os riscos de ataques a esse tipo de infraestrutura são muito baixos, já que terroristas geralmente estão menos preocupados em infligir danos à economia do que em impor perdas humanas para gerar clima de medo e pânico.

Polêmicas à parte, infelizmente, há poucas evidências que permitam avaliar o modo como os atentados de 11/09 alteraram a disposição dos atores privados em investir em mais segurança. Não está claro se, após os ataques terroristas da Al-Qaeda, os setores de infraestrutura crítica em mãos privadas realmente aumentaram seus gastos com segurança de forma sustentada. Em relação à oferta de serviços de segurança privada, infelizmente não há evidências que permitam avaliar se os ataques terroristas de 2001 tiveram algum impacto em termos de melhorar os indicadores da indústria de segurança privada. Não está claro, por exemplo, se no contexto pós-11/09, houve aumento dos programas de cooperação entre segurança privada e forças de segurança pública, elevação dos níveis de treinamento e qualificação de guardas e aumento dos índices de checagens de antecedentes dos candidatos a guarda. Essa situação chama por pesquisas nessa área, que entrou na agenda política dos EUA e deveria entrar na agenda acadêmica de Ciência Política.

\section{CONSIDERAÇÕES FINAIS}

No espaço de pouco mais de um século, a segurança privada nos EUA aumentou em tamanho e importância. Se no começo do século XX a segurança privada era vista com desconfiança pelo governo americano, no começo do século XXI, ela passou a ser vista não apenas como uma parceira no combate à criminalidade, mas também como uma parceira fundamental na promoção da segurança interna. Esse novo papel atribuído à segurança privada desafia o modo 
como tradicionalmente pensamos assuntos de segurança nacional, abordados pela disciplina de Ciência Política a partir de perspectivas teóricas centradas no Estado.

0 novo papel atribuído à segurança privada também desafia a governança da segurança doméstica dos EUA, colocando problemas de coordenação e regulação de atores não estatais que desempenham funções essenciais para a coletividade. Até 0 momento, o governo americano tem apostado na força do mercado para provocar um alinhamento de interesses entre Estado, interessado na proteção da nação, e patrocinadores e provedores de serviços de segurança privada, interessados na proteção de seus negócios e clientes. Essa aposta ocorre com base na crença de que esse suposto alinhamento de interesses seja suficiente para garantir a devida participação da segurança privada na governança da segurança nacional. Todavia, como mostrado, diversos fatores conspiram para que a segurança privada não seja empregada de acordo com o interesse público de promover a segurança nacional.

Diante desses fatos e dos riscos de novos ataques contra alvos em território nacional, a tendência é de que o governo americano estabeleça mais regulação na tentativa de fazer com que o setor de segurança privada aja de acordo com as prioridades de segurança dos EUA. Por motivos diversos, essa tendência para mais regulação já está em curso na Europa. Segundo Zedner (2006), até 2006, doze dos vinte e cinco países membros da União Européia haviam introduzido modificações nas regras até então existentes para o setor de segurança privada. E a Grã-Bretanha, que até o começo da década passada apostava na capacidade auto-regulatória do setor de segurança privada, baixou regulação estatal visando disciplinar esse setor de modo a torná-lo mais saudável do ponto de vista econômico e mais relevante no papel de auxiliar no combate à criminalidade.

Independentemente da tendência para mais regulação governamental sobre a segurança privada se confirmar ou não nos EUA, a participação desse setor de serviços na governança da segurança doméstica dos americanos parece um fato consolidado. Há aqui um tema de pesquisa que merece a atenção dos cientistas sociais, sobretudo dos interessados na análise dos novos padrões de governança na área de segurança. E o tema parece importante não apenas para aqueles diretamente interessados na sociedade americana. A segurança privada é um setor amplamente presente e reconhecido como recurso auxiliar no combate à criminalidade em diversos países. Alguns desses países têm como prioridade em sua agenda de segurança o problema do terrorismo, caso do Reino Unido e da Espanha. Dada a liderança dos EUA no combate ao terrorismo e o papel que esse país desempenha na difusão de modelos organizacionais, é possível que o padrão 
americano de governança da segurança doméstica, que atribui papel de destaque à segurança privada na proteção de infraestruturas críticas, também se reproduza em outras partes do mundo. A conferir.

\section{REFERÊNCIAS}

AVANT, Deborah. The emerging market for private military services and the problems of regulation. In: CHESTERMAN, Simon; LEHNARDT, Chia (Org.). From mercenaries to markets: the rise and regulation of private military companies. Oxford: Oxford University Press, 2007.

BAMBERGER, Kenneth. Global terror, private infrastructure, and domestic governance. In: CRAWFORD, Beverly (Org.). The impact of globalization on the United States: law and Governance. United States: Praeger Publishers, 2008. v. 2.

BLACK, Julian. Decentring regulation: the role of regulation and self-regulation in a "post-regulatory" world. Current Legal Problems, London, n. 54, p. 103-146, 2001. BRODEUR, Jean-Paul. High and low policing in post-9/11 times. Policing, United Kingdom, v. 1, n. 1, p. 25-37, 2007.

BURRIS, Scott; KEMPA, Michael; SHEARING, Clifford. Changes in governance: a cross-disciplinary review of current scholarship. Akron Law Review, Akron, v. 41, p. 1-66, 2008.

CEPIK, Marco. Serviços de inteligência: agilidade e transparência como dilemas de institucionalização. 2001. Tese (Doutorado em Ciência Política) - Instituto Universitário de Pesquisas do Rio de Janeiro, Rio de Janeiro.

CONNORS, Edward; CUNNINGHAM, William; OHLHAUSEN, Peter. Operation cooperation: a literature review of cooperation and partnerships between law enforcement and private security organizations. Washington: Department of Justice, Bureau of Justice Assistance, 1999.

CUNNINGHAM, William; TAYLOR, Todd. The hallcrest report: private security and police in America. Portland: Chancellor, 1985.

DIJK, Jan Van. The world of crime: breaking the silence on problems of security, justice and development across the world UK. London: Sage Publications, 2008.

FLYNN, Stephen. The edge of disaster: rebuilding a resilient nation. New York: Random House, 2007.

FRIEDMAN, Benjamin. Homeland security. Foreign Policy, United States, n. 49, p. 22-29, 2005. 
KAKALIK, James; WILDHORN, Sorrel. Private security in the United States. Washington, DC: U.S. Department of Justice, National Institute of Law Enforcement and Criminal Justice, Law Enforcement Assistance Administration, $1972.5 \mathrm{v}$.

MANNING, Peter. The United States of America. In: JONES, Trevor; NEWBURN, Tim (Org.). Plural policing: a comparative perspective. London: Routledge, 2006.

MORABITO, Andrew; GREENBERG, Sheldon. Engaging the private sector to promote bomeland security: law enforcement-private security partnerships. Washington: Department of Justice, Bureau of Justice Assistance, 2005. Disponível em: <www.ncjrs.gov/pdffiles1/bja/210678.pdf> . Acesso em: 15 maio 2011.

MORAN, Michael. The rise of the regulatory state in Britain. Parliamentary Affairs, London, v. 54, n. 1, p. 19-34, 2001.

PARFOMAK, Paul W. Guarding America: security guards and U.S. critical infrastructure protection. Washington: Congressional Research Service, The Library of Congress, $2004 a$.

.The U.S. contract security guard industry: an introduction to services and firms. Washington: Congressional Research Service, The Library of Congress, $2004 b$.

PICCIOTO, Sol. Regulatory networks and global governance. In: W.G. Hart Legal Workshop. The Retreat of the State: Challenges to Law and Lawyers. London: Institute of Advanced Legal Studies, University of London, 2006.

SHEARING, Clifford. A relação entre policiamento público e policiamento privado. In: TONRY, Michael; MORRIS, Norval (Org.). Policiamento moderno. São Paulo: Edusp, 2003.

SHEARING, Clifford; STENNING, Philip. Modem private security: its growth and implications. Crime and Justice, San Francisco, v. 3, p. 193-245, 1981.

SINGER, Peter. Corporate warriors: the rise of the privatized military industry and its ramifications for international security. International Security, Cambridge, v. 26, n. 3, p. 186-220, 2001/2002.

STEDEN, Ronald van; SARRE, Rick. The tragic quality of contract guards: a discussion of the reach and theory of private security in the world today. The Journal of Criminal Justice Research, United States, v. 1, n. 1, 2010.

WO0D, Jennifer; DUPONT, Benoît. Democracy, society and the governance of security. Cambridge: Cambridge University Press, 2006.

ZEDNER, Lucia. Liquid security: 'managing the market for crime control'. Criminology e Criminal Justice, United Kingdom, v. 6, n. 3, p. 267-288, 2006. 